\title{
IMPLEMENTASI SISTEM INFORMASI KUMPULAN DOA, TUTORIAL BERWUDHU, DAN MENGUMANDANGKAN ADZAN BERBASIS ANDROID
}

\author{
Imam Rifai $^{1}$, Imam Himawan ${ }^{2}$, Aswin Fitriansyah ${ }^{3}$ \\ Program Studi Teknik Informatika, Fakultas Teknik dan Ilmu Komputer, \\ Universitas Indraprasta PGRI \\ Jalan Raya Tengah No 80, Kelurahan Gedong, Pasar Rebo, Jakarta Timur \\ imam.rifai0117@gmail.com¹, imamhimawann@gmail.com², aswin.fitriansyah@gmail.com³
}

\begin{abstract}
Abstrak
Doa merupakan permohonan langsung kepada tuhan yang maha esa agar diberikan kebaikan, kemudahan, kesehatan dan jalan keluar dari kesulitan dan lain-lain. Akibat perkembangan teklonogi yang begitu pesat, banyak orang lupa akan pentingnya melakukan doa bahkan banyak anak-anak yang menyalah gunakan smartphone hanya untuk bermain game saja, padahal banyak sekali manfaat yang di dapat apabila kita bisa memanfaatkan kemajuan teknologi tersebut, salah satunya yaitu untuk belajar tentang doa-doa harian. Untuk mempermudah kita belajar doa-doa harian, maka dibuatlah sebuah aplikasi sistem informasi berbasis android. Aplikasi ini berfungsi sebagai media panduan belajar doa-doa harian serta mempermudah masyarakat khususnya anak-anak untuk proses pembelajaran dengan tampilan yang sangat mudah dipahami oleh pengguna. Aplikasi ini menggunakan metode penelitian waterfall yang terdiri dari 6 (enam) tahap yaitu rekayasa sistem, analisis, desain, coding, testing, serta maintenance. Hasil pengujian aplikasi ini sesuai dengan yang diharapkan dikarenakan semua tombol dan menu yang ada dapat berjalan dengan baik dan aplikasi mudah dipahami bagi anak-anak maupun orang tua.
\end{abstract}

Kata Kunci: kumpulan doa, tutorial berwudhu, mengumandangkan adzan, android.

\begin{abstract}
Prayer is a direct request to god almighty to be given goodness, ease, health and a way out of difficulties and others. Due to the rapid development of technology, many people forget the importance of doing prayers and even many children who misuse using smartphones just to play games, even though there are many benefits that can be if we can take advantage of technological advances, one of which is to learn about daily prayers. To make it easier for us to learn daily prayers, then created an android-based information system application. This application serves as a medium of daily prayer learning guide and makes it easier for the community, especially children, to learn with a view that is very easy for users to understand. This application uses waterfall research method consisting of 6 stages, namely system engineering, analysis, design, coding, testing, and maintenance. The results of testing this application are in accordance with what is expected because all the buttons and menus can run well and the application is easy to understand for children and parents.
\end{abstract}

Keywords: collection of prayers, ablution procedures, the call to prayer, android.

\section{PENDAHULUAN}

Pada era modern saat ini hampir semua organisasi memiliki sistem informasi. Sistem Informasi adalah kombinasi dari teknologi informasi dan aktivitas orang yang menggunakan teknologi itu untuk mendukung operasi dan manajemen. istilah sistem informasi yang sering digunakan merujuk kepada interaksi antara orang, proses algoritmik, data, dan teknologi. Sistem informasi berbasis android banyak digunakan karena penggunaan dan cara aksesnya yang mudah sehingga memudahkan dalam mencari suatu informasi.

secara umum sistem informasi dapat didefinisikan sebagai suatu sistem terintegrasi yang mampu menyediakan informasi yang bermanfaat bagi penggunanya (Athoillah \& Irawan, 2014)

Segala aktifitas yang kian padat menjadikan sebagian orang memiliki tingkat mobilitas yang tinggi. Seiring dengan perkembanganya teknologi, manusia cendurung lupa akan kewajiban dalam beragama. Contohnya seperti membaca doa, berwudhu yang benar, dan mengumandangkan adzan. 
Doa adalah simbol keimanan, tanda ketundukan seseorang kepada Allah SWT dan bukti keikhlasan kepada Allah SWT (Maulana \& Nurhayati, 2021). Manfaat hikmah dan tujuan dari berdoa dan berdzikir dalam Islam adalah sangat besar maknanya (Ratulangi, 2017).

menurut bahasa, Wudhu artinya Bersih dan Indah. sedangkan menurut istilah (syariah islam) artinya menggunakan air pada anggota badan tertentu dengan cara tertentu yang dimulai dengan niat guna menghilangkan hadast kecil (Pakaya Nurdin, 2019).

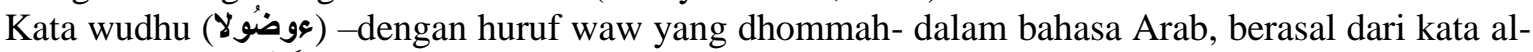

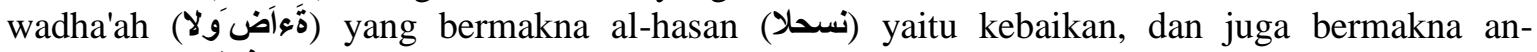
nadhzafah (قفظظنلا) yaitu kebersihan (Muhammad Ajib, 2019).

adzan berasal dari asal kata, ( يؤذّن - أذنّن (ئن) yang berarti al-i'lam atau pemberitahuan atau pengumuman (Hilmi, 2019).

\section{PENELITIAN RELEVAN}

Penelitian pertama adalah penelitian yang dilakukan oleh julham makatika, Linda Marlinda, dan Rachmat Yuniarto dengan judul aplikasi kumpulan doa harian bersumber Al-Quran dan Hadist berbasis android. Penelitian ini bertujuan Untuk dapat dijadikan sebagai media pembelajaran dan informasi seputar doa Islami sehari- hari serta bisa digunakan sebagai media pengamalan untuk mengutarakan bentuk rasa syukur kepada Allah SWT dimanapun dan kapanpun.

Penelitian kedua adalah penelitian yang dilakukan oleh Efmi Maiyana, dengan judul Pemanfaatan Android dalam perancangan aplikasi kumpulan doa. Penelitian ini bertujuan untuk mempermudah pencarian doa maupun pelafalan doa dalam kehidupan sehari-hari, Dengan adanya pemanfaatan android dalam perancangan aplikasi kumpulan doa ini juga sangat membantu admin dalam menginputkan doa-doa yang diperlukan tanpa batas

\section{METODOLOGI PENELITIAN}

Desain penelitian yang peneliti lakukan adalah dengan menggunakan metode grounded research dan metode observasi (pengamatan).

Metode grounded research yaitu suatu metode penelitian berdasarkan pada fakta dan menggunakan analisis perbandingan dengan tujuan mengadakan generalisasi empiris, menetapkan konsep, membuktikan teori, mengembangkan teori, pengumpulan dan analisis data dalam waktu yang bersamaan (Marsiani, 2018).

Metodologi Penelitian sistem yang digunakan adalah Waterfall, dengan tahapan Rekayasa sistem, analisis, Desain, Pengkodean, Pengujian, Pemeliharaan. Seperti gambar berikut berikut:

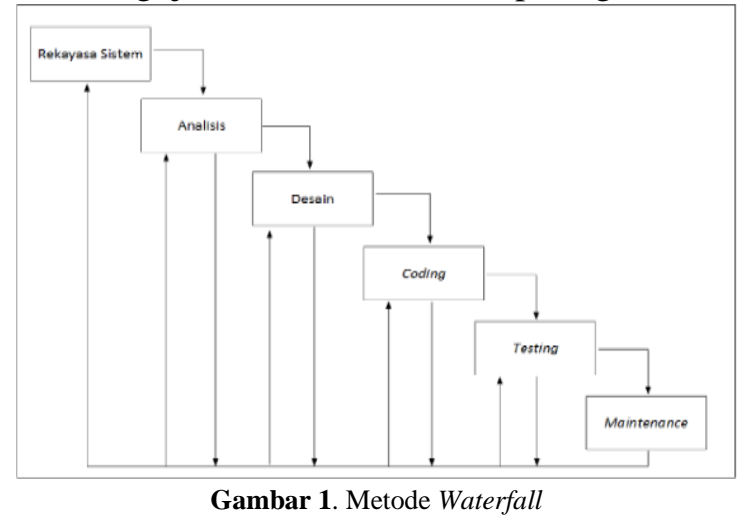

\section{HASIL DAN PEMBAHASAN}

Permasalahan yang ada saat ini adalah proses pembelajaran masih menggunakan metode konvensional, terutama dalam pembelajaran doa-doa harian. Maka dari itu peneliti bekeinginan membuat sebuah aplikasi mengenai informasi kumpulan doa, tutorial berwudhu, serta mengumandangkan adzan berbasis Android.

Berikut adalah perancangan flowchart dan tampilan hasil uji coba untuk Sistem informasi kumpulan doa, tutorial berwudhu, serta mengumandangkan adzan berbasis Android. 
Jurnal Riset dan Aplikasi Mahasiswa Informatika (JRAMI)

Vol प3 № $\mathrm{Cl}$ Tahun 2022

e-ISSN : 2715-8756

\section{Menu Utama}

Flowchart Menu utama

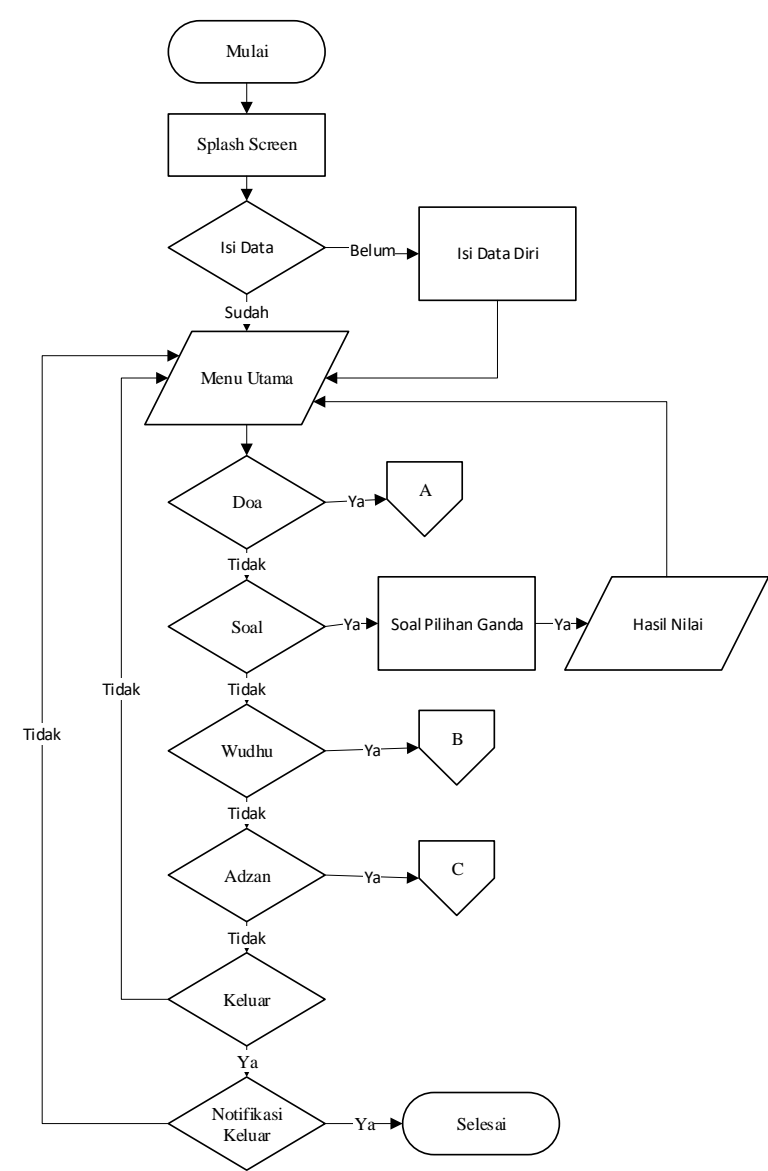

Gambar 2. Flowchart Menu Utama

\section{Menu Kumpulan Doa}

Flowchart Menu Kumpulan Doa

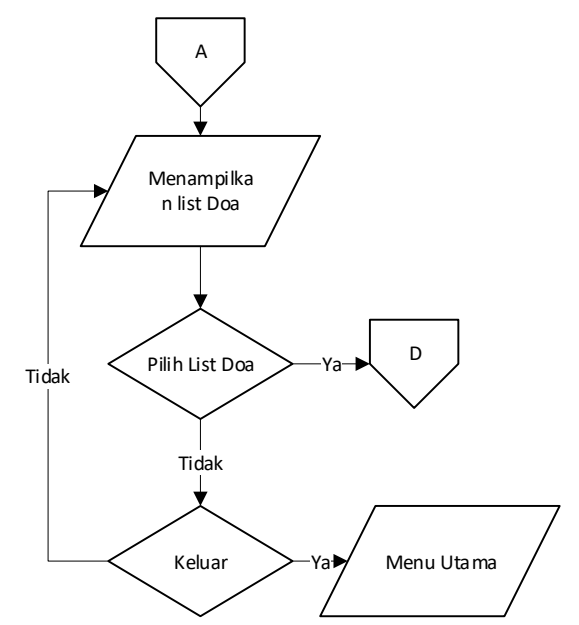

Gambar 3. Flowchart Menu Kumpulan Doa 
Jurnal Riset dan Aplikasi Mahasiswa Infarmatika (JRAMI)

Vol प3 № CI Tahun 2022

e-ISSN : 2715-8756

\section{Menu Doa}

Flowchart Menu Doa

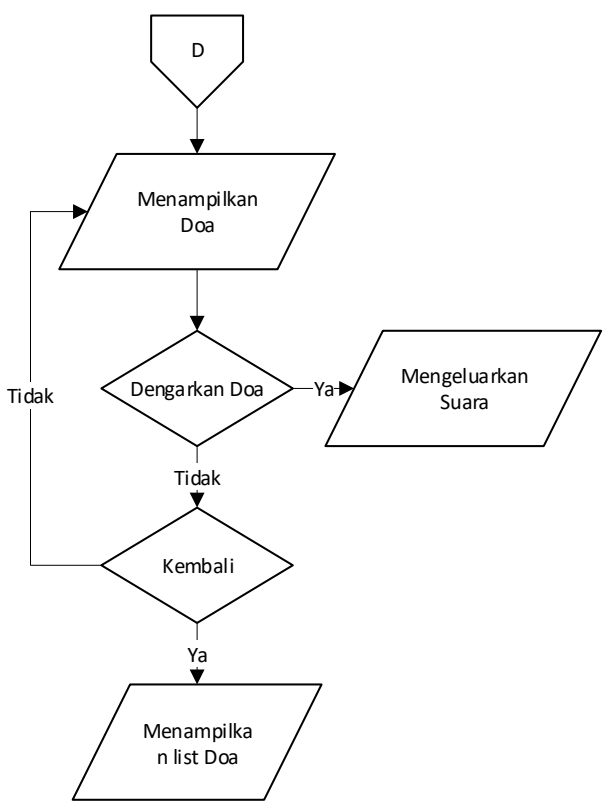

Gambar 4. Flowchart Menu Menu Doa

\section{Menu Wudhu}

Flowchart Menu Wudhu

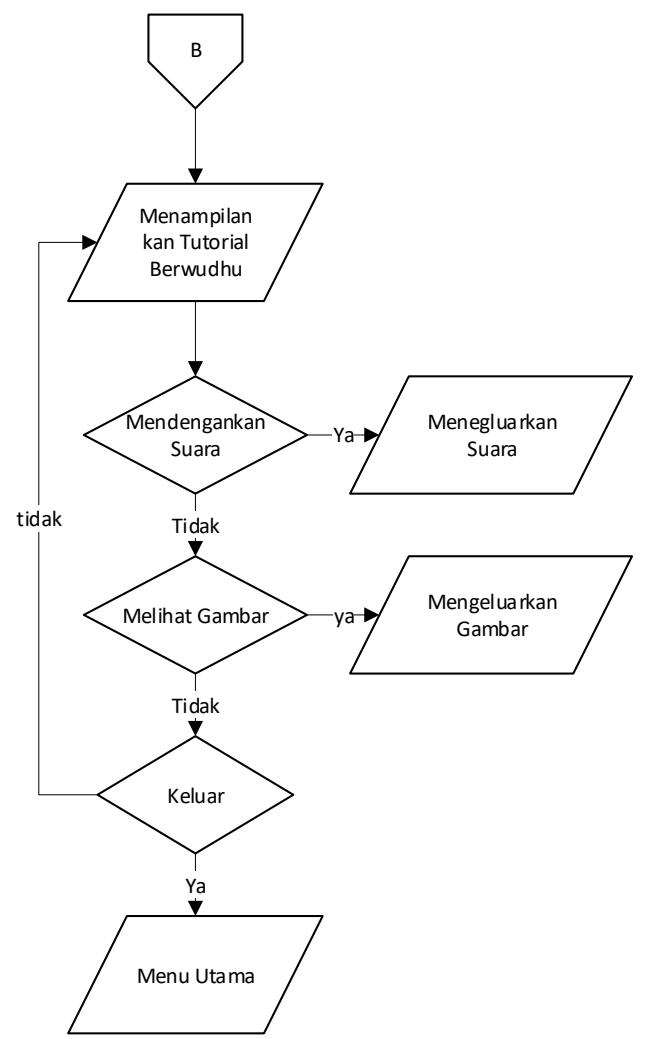

Gambar 5. Flowchart Menu Wudhu 


\section{Menu Adzan}

Flowchart Menu Adzan

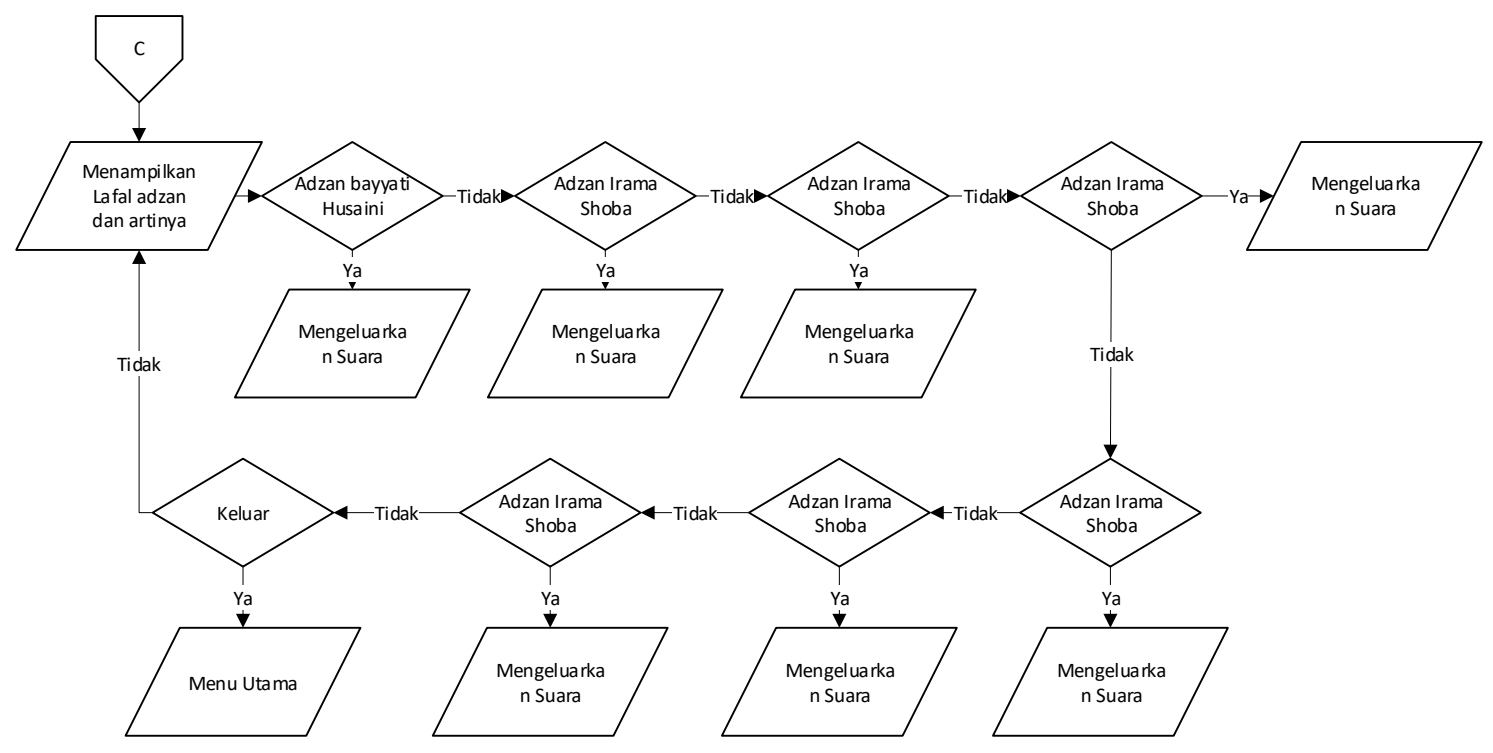

Gambar 6. Flowchart Menu Adzan

\section{Tampilan Aplikasi}

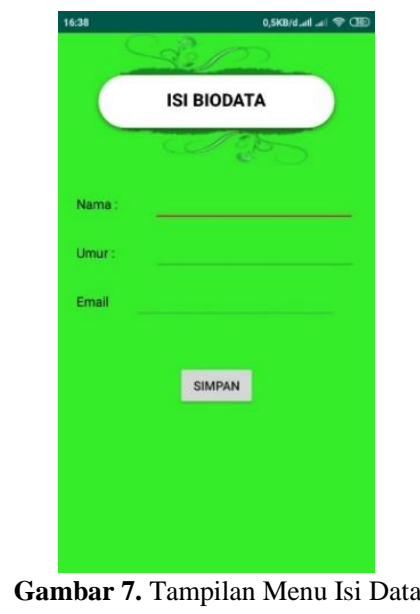

Pada tampilan Menu Isi Data terdapat form pengisian data agar data tersimpan di dalam database

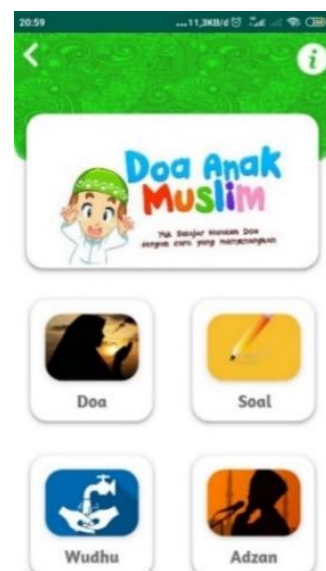

Gambar 8. Tampilan Menu Utama 
Pada tampilan Menu Utama terdapat 4 tombol menu yang dapat diakses, antara lain adalah doa, soal, wudhu, adzan.

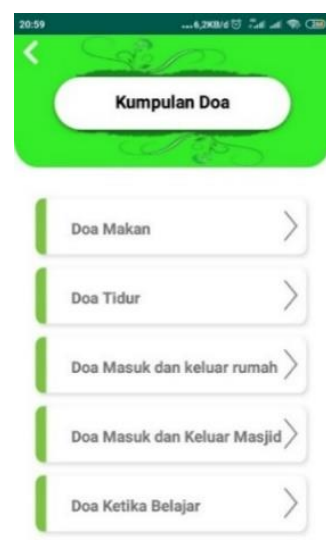

Gambar 9. Nama Doa

Pada tampilan Menu doa terdapat nama-nama doa yang dapat diakses dan menapilkan doa yang terdapat didalam nama tersebut.

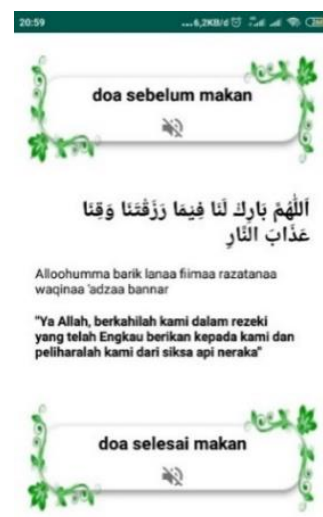

Gambar 10. Tampilan Menu Doa

Pada tampilan Menu doa terdapat bacaan-bacaan doa yang telah dipilih, doa terdiri dari tulisan arab, latin, arti, dan juga suara.

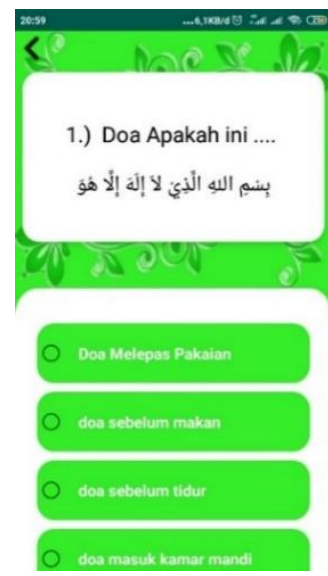

Gambar 11. Tampilan Menu Latihan Soal 
Pada tampilan Menu Latihan Soal terdapat 10 buah pertanyaan secara acak yang dapat dijawab

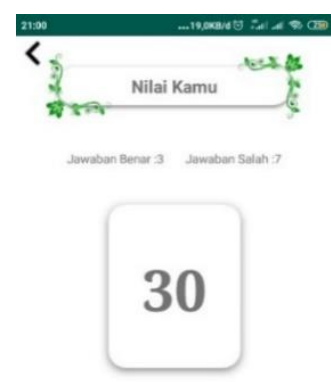

Gambar 12. Tampilan Menu Nilai Latihan Soal

Pada tampilan Menu Nilai Latihan Soal terdapat nilai dari 10 buah pertanyaan yang sudah dijawab

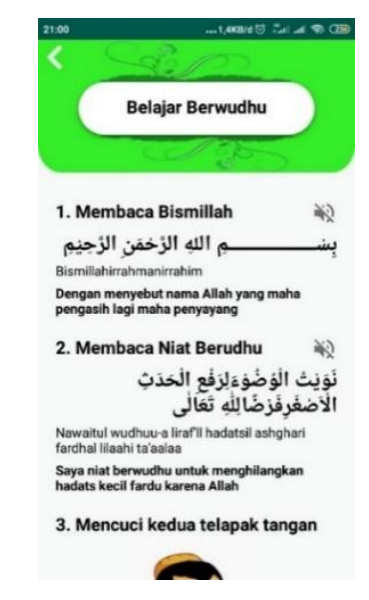

Gambar 13. Tampilan Menu wudhu

Pada tampilan menu wudhu, terdapat tatacara berwudhu yang baik dan benar, tatacara wudhu tersebut terdiri dari bacaan-bacaan wudhu, serta gambar gerak tatacara wudhu.

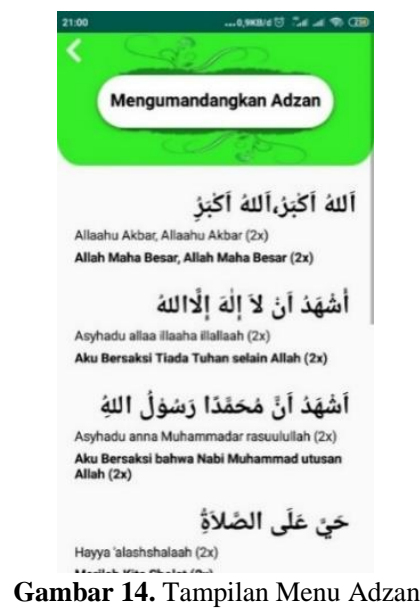

Tampilan ini terdapat lafal adzan baik tulisan arab, latin, serta arti dari bacaan adzan, terdapat pula lantunan adzan dari berbagai irama. 


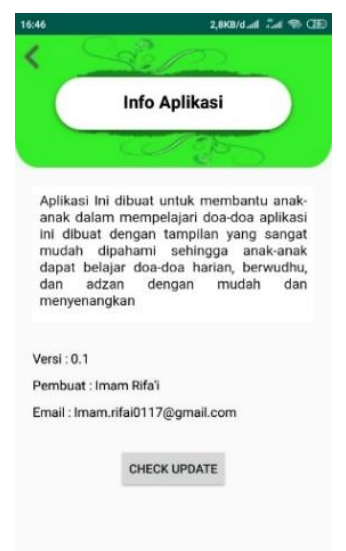

Gambar 15. Tampilan Menu Info Aplikasi

Pada menu info aplikasi terdiri dari penjelasan aplikasi, versi aplikasi serta data pembuat aplikasi.

\section{SIMPULAN}

Berdasarkan hasil sistem yang peneliti lakukan, maka dapat disimpulkan dan memberikan saran yang berhubungan dengan pembahasan berdasarkan penulisan, dengan perkembangan teknologi yang begitu pesat peneliti menggabungkan pembelajaran doa-doa harian dengan teknologi agar anak-anak menjadi lebih tertarik untuk mempelajari doa-doa harian tersebut. Dengan adanya aplikasi ini maka anak-anak akan lebih mudah dalam mempelajari doa-doa harian, tutorial berwudhu, serta mengumandangkan adzan, yang akan membuat mereka menjadi terbiasa berdoa sebelum beraktifitas. Oleh karena itu, aplikasi ini memiliki kelemahan, yaitu hanya dapat dijalankan melalui Smartphone berbasis Android dan harus terkoneksi dengan internet.

\section{DAFTAR PUSTAKA}

Athoillah, \& Irawan. (2014). Mobile Berbasis Android Untuk. Perancangan Sistem Informasi Mobile Berbasis Android Untuk Kontrolpersediaan Barang Di Gudang, 1(January), 1-6.

Hilmi, A. (2019). Adzan, Hanya Sebagai Penanda Waktu Shalat? (Fatih (ed.)). Rumah Fiqih Publishing. https://www.rumahfiqih.com/pdf/pdf/219.pdf

Marsiani, E. S. (2018). Rancangan Aplikasi Inventarisir Bahan Pembuat Mukena pada PT. Tatuis Bogor dengan Menggunakan Java. STRING (Satuan Tulisan Riset Dan Inovasi Teknologi), 3(1), 9. https://doi.org/10.30998/string.v3i1.2722

Maulana, M. R., \& Nurhayati, N. (2021). Perancangan Aplikasi Hafalan Doa Dan Hadits Berbasis Android. ... ) Journal, 161-172. http://e-journal.potensi-utama.ac.id/ojs/index.php/ITJournal/article/view/1036

Maiyana, E. (2018). Pemanfaatan Android Dalam Perancangan Aplikasi Kumpulan Doa. Jurnal Sains Dan Informatika, 4(1), 54-65. https://doi.org/10.22216/jsi.v4i1.3409

Pressman, Roger S. 2012. Rekayasa Perangkat Lunak - Buku Satu, Pendekatan Praktisi (Edisi 7). Yogyakarta: Andi.

Nuraini, R. (2015). Desain Algorithma Operasi Perkalian Matriks Menggunakan Metode Flowchart. Jurnal Teknik Komputer Amik Bsi, 1(1), 144-151.

Muhammad Ajib. (2019). Fiqih Wudhu Versi Madzhab Syafi'iy (Aufa Adnan Asy-Syaafi'iy (ed.)). Rumah Fiqih Publishing. https://www.rumahfiqih.com/pdf/pdf/210.pdf

Pakaya Nurdin, T. A. R. (2019). Perancangan Aplikasi Pengenalan Sholat Dan Wudhu Menggunakan (Ar) Argumented Reality..

Ratulangi, U. S. (2017). Rancang Bangun Aplikasi Game Edukasi Hafalan Doa Agama Islam. Jurnal Teknik Informatika, 12(1). https://doi.org/10.35793/jti.12.1.2017.17791 